\title{
Teatro y Fulgor. Aproximaciones a la obra de Isidora Aguirre
}

\author{
Marcia Martínez C., Jessica Améstica T., Nora Fuentealba R., \\ y VJeRA Milosevic M. (eds.) (2016). \\ Ediciones Universitarias de Valparaíso, Pontificia Universidad Católica \\ de Valparaíso, Colección Dársena Lecturas, 206 páginas, \\ ISBN: 978-956-17-0685-9
}

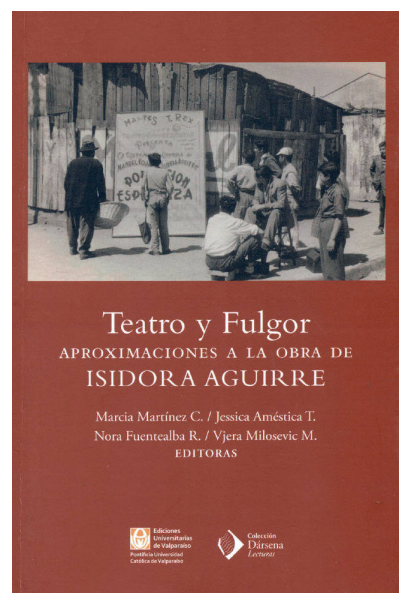

Javiera Larraín George

Pontificia Universidad Católica de Chile - CONICYT, Chile

javiera.larraing@gmail.com

Fecha de recepción: 15/11/2018. Fecha de aceptación: 16/02/2019.

Isidora Aguirre vivió una vida intensa mucho antes de convertirse en una de las dramaturgas más destacadas de la historia teatral chilena. Desde temprana edad, recibió una educación centrada en las artes, siempre bajo la atenta mirada de su madre, la pintora María Tupper Hunneus. Sus comienzos en la dramaturgia se remontan a 1952, año en que produciría sus primeras piezas teatrales: comedias como Carolina y La Dama del Canasto. Su trabajo evolucionaría con el tiempo hacia una obra con un profundo compromiso social que buscaba no solo reflejar, sino también denunciar y poner en cuestionamiento la situación política del país. Pero antes de ser "atrapada por el teatro" -como ella misma comentaría en una de sus últimas entrevistas-, exploraría los campos de la escritura e ilustración infantil y cursaría estudios de dirección cinematográfica y trabajo social. Pese a su condición de artista interdisciplinaria, en la mayoría de las ocasiones que se enuncia el nombre de Isidora Aguirre, automáticamente se piensa en La Pérgola de las flores, comedia musical estrenada en los 60 y vista por miles (de miles) de chilenos. La 'Nene' -como le decían sus más allegados- bromeaba al respecto, diciendo que La Pérgola era "aquella [obra] que pagaba los dulces de la merienda de la tarde". Cabría preguntarse si, a partir de las innumerables anécdotas que se cuentan sobre la vida de la autora, y en relación-además-a la gran cantidad de estudios de su obra, se puede definir la figura de Isidora Aguirre, para explicar -de paso- por qué pareciera que existió, por muchos años, un desconocimiento frente a su trabajo dramatúrgico más allá de La Pérgola de la flores.
Es esta inquietud -precisamente- la que articula el libro Teatro y Fulgor. Aproximaciones a la obra de Isidora Aguirre, editado por Marcia Martínez C., Jessica Améstica T., Nora Fuentealba R. y Vjera Milosevic M., un estudio que busca revisitar la obra de la dramaturga a partir de un trabajo colaborativo a través de la selección de un conjunto de ensayos que repasan su trayectoria. Pues, si bien, en los últimos años ha surgido un creciente interés en sus obras, se hace necesario retornar constantemente sobre las mismas. Tal como señalan las editoras, el objetivo del presente libro descansaría en: "volver a mirar la obra de Aguirre desde diversas voces, y aunque ya se le ha mirado con atención, sigue siendo necesario contribuir a la circulación de sus creaciones, de su nombre, de sus escenas y de sus ímpetus" (8).

La organización de los textos que conforman parte de este libro guarda relación con cuatro entradas de lectura distintas - pero todas en un constante diálogo y una fuerte sintonía- para abordar la obra dramatúrgica de Aguirre. La primera de ellas arroja una perspectiva académica sobre su trabajo, y es provista por las cuatro editoras, que componen un primer apartado correspondiente a las 'Lectura Preliminares', organizada por los ensayos "Reflexiones en torno a ¡Subiendo... último hombre! (2005) de Isidora Aguirre" de Nora Fuentealba Rivas, "Historia/ Aguirre" de Vjera Misolevic Milic, "El amor también puede ser un espejo negro: lectura a propósito de Esta difícil condición y Magy ante el espejo de Isidora Aguirre” de Jessica Améstica Toledo y “Estrategias 
para abrazar la historia: el teatro de Isidora Aguirre" de Marcia Martínez Carvajal.

En el primero de estos documentos, Nora Fuentealba entrega una reflexión en torno a los discursos de derrota que es posible apreciar en dos piezas -no tan estudiadas- de la autora, en un intento de batallar -por parte de Aguirre- los discursos nostálgicos, con la proyección de invitar al hombre a habitar una nueva historia. Por su parte, Vjera Milosevic realiza una defensa argumentativa que intenta explicar por qué aún es necesario revisitar -una y otra vez- la obra de Aguirre, poniendo un especial énfasis en las formas de apropiación de la historia en su labor como dramaturga. Asimismo, Jessica Améstica -en el tercer ensayo de esta sección- instala la pregunta por la perspectiva amorosa en dos textos de Aguirre como un mecanismo para abordar la búsqueda identitaria de sujetos/personajes incapaces de comunicarse con otros y consigo mismos. Finalmente, Marcia Martínez repasa la producción dramatúrgica de Aguirre desde una clave historiográfica que busca entrelazar puntos de encuentro con el teatro chileno reciente. Estos cuatro primeros estudios tienen en común el proveer de reflexiones en torno a la memoria, el olvido, la historia y-por sobre todo- el amor.

Esta perspectiva académica de la obra de Aguirre prosigue en la segunda sección del libro, correspondiente a 'Artículos y Panoramas', que pone especial atención a los contextos históricos, los imaginarios político-sociales de sus obras y la importante noción de comunidad que se soslaya -de una u otra manera- en gran parte de su trabajo. Aquí, en el primero de estos textos, "Aristas de una revolución teatral de masas. Imaginarios de dirección, coreografías grupales y estrategias dramatúrgicas en Isidora Aguirre, Patricio Bunster y Víctor Jara", Andrés Grumann se concentra en comprender cuáles son las relaciones entre el compromiso político y la forma teatral-coreográfica en las que dialogaron Aguirre (dramaturgia), Bunster (coreografía) y Jara (dirección) a partir del contexto artístico de la Unidad Popular, en particular en torno a la actividad del TEPA (Teatro Experimental Popular Aficionado). El segundo ensayo, titulado "Los papeleros: mensaje, códigos teatrales y vigencia histórica teatral", su autor, Juan Villegas, realiza una lectura acabada de la mencionada obra, poniendo en tensión las valoraciones estéticas e ideológicas que el texto y su consecuente montaje en 1963 provocaron. A su vez, Alicia del Campo, quien cierra esta sección; escribe "Isidora Aguirre, una autora esencial" que presenta un minucioso estudio sobre su poética dramatúrgica, atravesada por sus preocupaciones en torno a la construcción del sujeto femenino, la representación de lo popular bajo los paradigmas del teatro épico y el rol del testimonio como un medio para revisar la historia.

Una segunda entrada de lectura está organizada en el diálogo directo con la autora, en la sección de 'Entrevistas', a partir de los escritos "Recoger la hazaña de los muertos para entregársela a los vivos”, una mesa redonda que recoge la conversación entre Isidora Aguirre y los artistas Eugenio Guzmán y Rine Leal. Asimismo, "Entrevista a Isidora Aguirre”, a cargo de Eduardo Guerrero, quien lúcidamente invita a la autora a mirar en retrospectiva la totalidad de su trabajo teatral.

Por otra parte, una tercera línea de apertura se propone a partir de la exploración pragmática de los contextos de recepción de sus montajes, en la sección 'Lo político y lo histórico' en relación a los ensayos "Nota sobre Los que van quedando en el camino de Isidora Aguirre y su montaje en enero del 2010" por Pía Gutiérrez y "Sobre Los que van quedando en el camino" de Volodia Teitelboim. Ambos textos funcionan a modo de contrapunto, ya que realizan un ejercicio crítico en torno a la recepción de este montaje en dos contextos de producción sumamente disímiles. Por una parte, Teiltebom da cuenta de su percepción como público de la pieza original en 1963, en pleno albor del proyecto de la Unidad Popular que llevaría a Allende al poder. Mientras que Gutiérrez analiza la propuesta de Guillermo Calderón -estrenada en 2010, en el marco de las celebraciones del Bicentenario chileno- quien decide convocar al elenco original, que presenció el propio Teilteboim en los 60, como un acto político que enseña la resistencia de aquellos cuerpos que, al igual que la historia de la matanza de los campesinos de la localidad de Ranquil que relata Aguirre y que el proyecto socialista-allendista, han quedado olvidados en el camino.

Finalmente, en la sección 'Primera Persona', la última entrada de lectura que las editoras articulan, se incluye un registro de puño y letra de Aguirre, "Mi experiencia con el teatro regional", y una reflexión de Andrea Jeftanovic sobre la organización del archivo material de la autora tras su muerte, bajo el nombre de "El derecho a la mirada. Cartografía gráfica del Archivo Isidora Aguirre".

Teatro y Fulgor. Aproximaciones a la obra de Isidora Aguirre es -a todas luces- una revisitación acuciosa y sensible a la obra de esta autora. Como destaca lúcidamente Marcia Martínez en su escrito, el teatro de Isidora Aguirre es un llamado a no dejar que la Historia nos pase por delante: "se advierte el clamor 
porque las fechas, los monumentos y las conmemoraciones no sean un conceso para el olvido [...], se anhela que la justicia no siga siendo reemplazada por la reparación y la reconciliación, que no suceda más el simple desplazamiento de lo legal a lo simbólico" (39-40). De esta forma, en el trabajo de Aguirre es posible ver y comprender una apropiación de la Historia, en donde la fraternidad íntima de la comunidad popular y cotidiana, se abriría paso a través del diálogo con la tradición del teatro chileno. Por ende, su dramaturgia no solo llora y pide justicia por los muertos que la historia oficial pretende olvidar, sino que también clama porque los nombres, los lugares y las fechas de aquel correlato histórico no sean olvidados, porque para Aguirre -a final de cuentas- la historia vuelve tras sus propios pasos y las injusticias de antaño no son más que un chispazo de las infamias del mañana, como bien señala Martínez en su estudio de filiación entre la dramaturgia de la autora con las nuevas autorías chilenas.

En consecuencia, la obra de Isidora Aguirre pareciera ser -exactamente- eso: un fulgor, un resplandor, una chispa que brilla imposible de apagarse frente al peso de una Historia amarga, que -con dolor y pesadumbre- se vuelve hoscamente cíclica. A modo de ejemplo, cómo olvidar la cruenta escena del patrón que le habla a los papeleros -en la obra homónima de Aguirre- a través de un megáfono; mostrando a sus trabajadores estremecidos de escuchar la voz de un patrón que en su incorporeidad parece más tangible, intransigente y presente que nunca. Y cómo no pensar -hoy por hoy- en la seguidilla de huelgas sindicales que se agolpan en el Chile actual, aquellas huelgas en las que los trabajadores exigen sentarse a una mesa a dialogar con sus jefes en pos de mejoras laborales y salariales, mientras ven cómo estos les responden por videos institucionales publicados en internet, operando con la misma intangibilidad que Aguirre proponía hace décadas. También, cómo no asociar la proyección de la mujer idealizada en Magy ante el espejo con los imperantes cánones de ficcionalidad y representación que prometen la gran variedad de filtros que promueven las actuales redes sociales.

Este libro parece recordarnos constantemente que en la obra de Aguirre, los pasajes negros de nuestra pasada historia vuelven sin cesar a la realidad presente que vivimos. He ahí, en efecto, la actualidad de su legado. Pero la dramaturgia de la autora no se yergue únicamente desde la soledad de una denuncia que clama para que no se olviden aquellos que fueron dejados en el camino, sino que también busca que se construya un futuro en torno al amor y a la comunidad. Ambos son para Aguirre el fuego que abrasa y provee de porvenir; son la experiencia con la que se intenta edificar una nueva verdad y, tal vez, así, vencer esta Historia hostil. Esa es la invitación de Aguirre que las editoras buscan promover en el trazo de cada uno de los artículos aquí compilados, puesto que, tal como enfatiza la autora en su entrevista con Guerrero, la rebeldía se construye sobre aquellos que dieron la vida (157). Es así que, si Aguirre quería mover -cual gesto brechtiano- a la acción por medio de su teatro, este libro busca movilizar la relectura y la reflexión en torno al teatro de la autora, como una invitación a la rebeldía, pero, por sobre todo, al amor. Es imposible pensar -por cierto- el teatro de Aguirre sin entender los actos de amor que hay inscritos en él, sin entender que sus personajes hablan desde el dolor de la pérdida, pero también desde el calor de los afectos. A final de cuentas, Aguirre entiende-como sentencia en Los papeleros- que "el teatro cuenta hechos tan absurdos como son y a nosotros corresponde pensar en la solución".

\section{Bibliografía}

» Martínez C., Marcia et al. (2016). Teatro y Fulgor. Aproximaciones a la obra de Isidora Aguirre. Valparaíso: Ediciones Universitarias de Valparaíso, Pontificia Universidad Católica de Valparaíso. 